\title{
Optimization of Flavonoid Production in Plant Cell Culture of Thevetia peruviana Elicited with Methyl Jasmonate and Salicylic Acid
}

\author{
Mateo David León Durán ${ }^{*}$ \\ https://orcid.org/0000-0001-5328-9838 \\ Mario Evelio Arias Zabala ${ }^{1}$ \\ https://orcid.org/0000-0001-8190-7760
}

Guillermo Antonio Correa Londoño'
https://orcid.org/0000-0001-7020-2546

${ }^{1}$ National University of Colombia, Medellín, Colombia.

Editor-in-Chief: Alexandre Rasi Aoki

Associate Editor: Jane Manfron Budel

Received: 2021.01.15; Accepted: 2021.06.29.

${ }^{*}$ Correspondence: matleon@unal.edu.co; Tel.: +57 3103683620 (M.D.L.D.).

\section{HIGHLIGHTS}

- The addition of MeJa and SA on the $6^{\text {th }}$ day for $24 \mathrm{~h}$ resulted in a 1.07 and 1.3 times increase in total flavonoid content compared to the control culture.

- Optimizing parameters such as MeJa and SA concentration, addition time and harvest time resulted in total flavonoid content 4.14 and $3.75 \mathrm{mg} \mathrm{EQ} / \mathrm{g} \mathrm{DW}$, respectively.

\begin{abstract}
Thevetia peruviana is a medicinal plant that has valuable secondary terpenoid-type metabolites and phenolic compounds. Some flavonoid compounds of pharmaceutical interest stand out in the latter group. The concentration of these bioactive compounds in natural conditions is limited by environmental; therefore, it has been considered necessary to make in vitro plant cell suspension cultures that admit the use of elicitors to increase the content of active principles. Accordingly, in this study, for the optimization of flavonoid production in cell suspension culture of $T$. peruviana, different parameters related to elicitation with methyl jasmonate (MeJa), and salicylic acid (SA) were evaluated, at stirred flask scale. Firstly, $3 \mu \mathrm{M} \mathrm{MeJa}$ and 300 $\mu \mathrm{M}$ SA were added separately in cell cultures of $T$. peruviana, to assess their potential effects. Secondly, several experimental conditions were evaluated, for optimization purpose. In the first part, MeJa and SA increased the total flavonoid content, in 1.07 and 1.3 times, respectively, compared to the control culture; in the second part, total flavonoid content produced in MeJa mediated cell suspension cultures were $4.14 \mathrm{mg}$ $\mathrm{QE} / \mathrm{g} \mathrm{DW}$ (milligrams of quercetin equivalent per gram of dry biomass) with: concentration $0.3 \mu \mathrm{M}$, addition time day 5 and harvest time $90 \mathrm{~h}$. On the other hand, total flavonoid content produced in SA mediated cell suspension cultures were $3.75 \mathrm{mg} \mathrm{QE} / \mathrm{g} \mathrm{DW}$ with: concentration $100 \mu \mathrm{M}$, addition time day 0 and harvest time $96 \mathrm{~h}$. Elicitation of cell suspension cultures of $T$. peruviana with MeJa and SA under their ideal parameter values increased flavonoid content.
\end{abstract}

Keywords: elicitors; flavonoid compounds; plant cell cultures; Thevetia peruviana. 


\section{GRAPHICAL ABSTRACT}

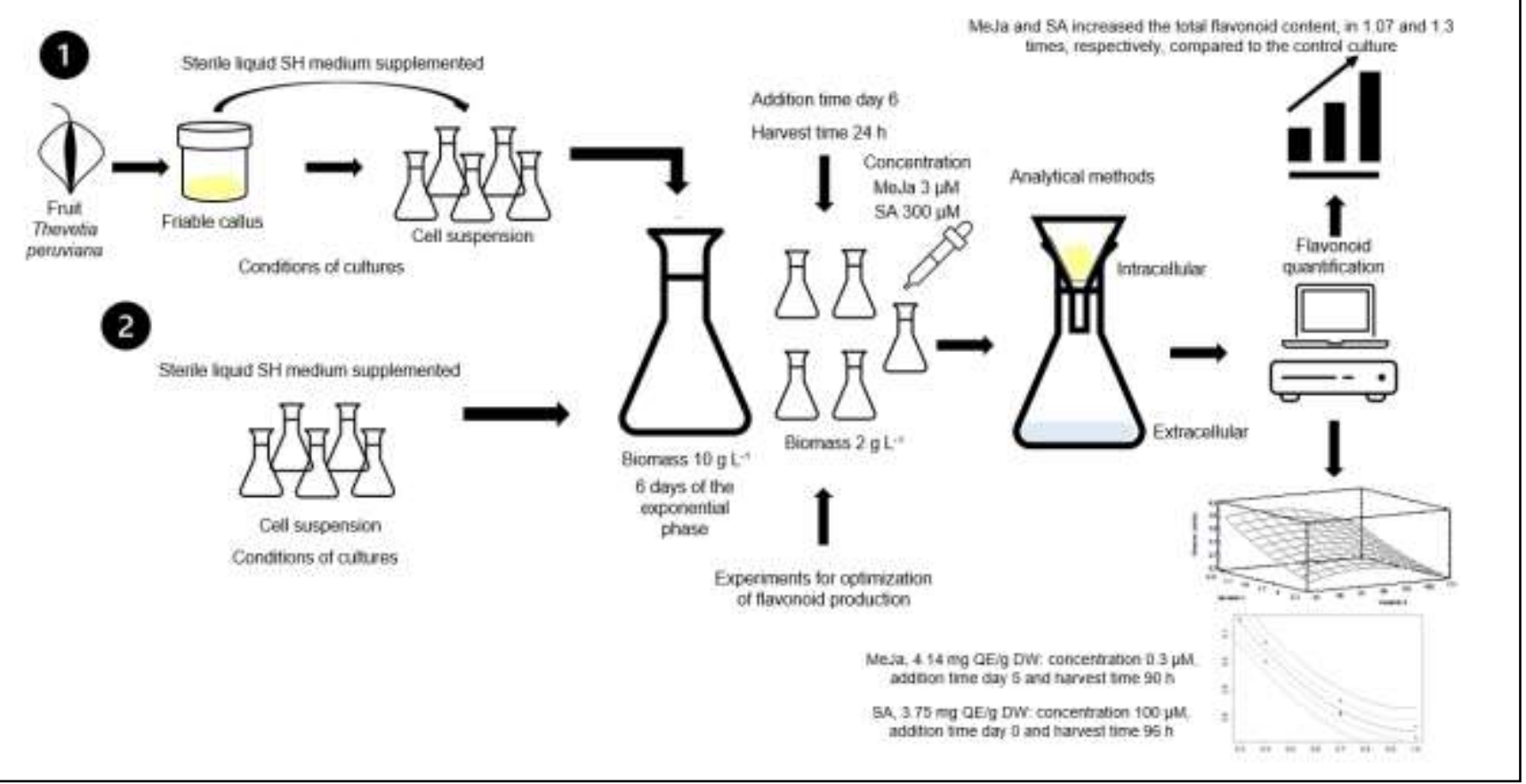

\section{INTRODUCTION}

Thevetia peruviana is a plant species, belonging to the Apocynaceae family. It is commonly called yellow oleander, and it is grown as ornamental in South America [1]. It is distinguished for its flowers in form of a funnel with five petals and fruits in form of a triangle [2]. Some therapeutic properties such as cardiovascular, anti-carcinogenic, antimicrobial, antioxidant, anti-inflammatory and immunomodulatory activities are attributed to this species [3].

Production of terpene and phenolic type compounds has been reported in leaves [4], bark [5], flowers [6], fruits [7] and seeds [8] of T. peruviana; in the latter group of metabolites stand out the flavonoids kaempferol and quercetin, which have three rings in their structure, because they derive from aromatic amino acids such as phenylalanine (Phe) and tyrosine (Tyr) [9]. These compounds are produced by acetate/malonate, shikimic acid, pentose phosphate metabolic pathway [10], and through metabolism of phenylpropanoids [11]. The flavonols are the most promising group in flavonoids due to their antimicrobial and anti-carcinogenic properties, and for its potential in the treatment of cardiovascular diseases [12].

The amount of secondary metabolites that plant species produces are affected by biotic and abiotic conditions that accompany cultivation [13]. In recent years, several studies have reported the use of elicitors in cell suspension cultures to increase the production of metabolites of pharmaceutical interest [14]. The plants naturally produce bioactive compounds when placed in vitro, but its content is very low due to the brief stationary phase that in vitro cultured plants present, because of the inhibition by the action of enzymes [15]. Elicitors such as MeJa and SA are frequently used to enhance the secondary metabolites production in plant cell cultures, since they act as regulators of defense responses, by initiating signals that active multiple secondary biosynthetic pathways and their relevant genes [16,17].

El-Ashry and coauthors [18] enhanced accumulation of rutin in calli cultures of Gardenia jasmonides using Phe and SA. Liu and coauthors [19] increased content and yield of chlorogenic acid in G. jasminoides cell suspension cultures elicited with MeJa and SA. Jacob and Thomas [20] focused their study in the production of flavonoid compounds adding silver nitrate, copper sulfate and SA in cell suspension culture of Ocimum tenuiflorum. Al-Khairy and Naik [21] obtained high concentrations of phenolic compounds from cell suspension cultures of Phoenix dactylifera L. using yeast extract, salicylic acid, cadmium chloride, and silver nitrate. MeJa and SA regulate the oxidative stress in plants; furthermore, they have been used to stimulate the production of secondary metabolites in tissue cultures, suspension cells, or cultures of calluses in various plant species [22-24]. 
Researches conducted by Arias and coauthors [25] and Tabata [26] in in vitro cultures of T. peruviana reported the increase of cardiotonic glycosides and peruvosides using MeJa and SA elicitors. A recent study published by Mendoza and coauthors [7] reported cardiac glycosides, phenolic, and flavonoids compounds in cell suspension cultures of $T$. peruviana during the exponential grown phase. Considering that secondary metabolites are of pharmaceutical interest, it is necessary to explore ways of large-scale production at industrial levels, which have already been achieved with plants such as Taxus sp. that produces paclitaxel [26]; Lithospermum erythrorhizon that produces shikonin [27]; Panax ginseng for the production of ginsenosides through adventitious root cultures [28]; Catharanthus roseus that produces vincristine and vinblastine, used for treatment of leukemia [29].

In this study different parameters of MeJa and SA were evaluated to optimize the production of secondary flavonoid-type metabolites in cultures of suspension cells of $T$. peruviana at scale of stirred flask. Effects of operational parameters such as: elicitor type, concentration, addition time, and harvest time were studied in detail.

\section{MATERIAL AND METHODS}

The experimental process included two phases. In the first one, MeJa and SA were added, under constant conditions: MeJa 3 and SA $300 \mu \mathrm{M}$ elicitation $6^{\text {th }}$ day for $24 \mathrm{~h}$, to some suspension cultures of $T$. peruviana, that were available at the Bioconversion Laboratory of Universidad Nacional de Colombia, Sede Medellín (Table 1, experiment 1).

During the second phase, we used response surface methodology to achieve the values of the operational parameters which were expected to generate the maximum content of flavonoid compounds (Table 1, experiments 2 to 4 for MeJa and 6 to 7 for SA). In the last experiment for each of the elicitors, both addition time and harvest time were fixed, letting only concentration to variate (Table 1, experiments 5 and 8). The parametric exploration regions were chosen in accordance with the different paths followed each of the elicitors. These experiments were fitted using second order polynomial models.

Table 1. Experimental conditions to evaluate the production of total flavonoid compounds in cell suspension cultures of Thevetia peruviana.

\begin{tabular}{ccccc}
\hline Experiments & Elicitor & Addition time (days) & Concentration $(\boldsymbol{\mu M})$ & Harvest time $(\mathbf{h})$ \\
\hline 1 & MeJa & 6 & 3 & 24 \\
2 & $\mathrm{SA}$ & 6 & 300 & 24 \\
3 & MeJa & 0,6 , and 12 & 1,3 , and 5 & 12,24 , and 96 \\
4 & MeJa & 8 & $0.85,1,1.5,2$, and 2.14 & $81,84,96,108$, and 110 \\
5 & MeJa & $0.25,1,5,9$, and 10 & $0.3,0.4,0.7,1$, and 1.1 & 90 \\
6 & MeJa & 5 & $0.3,0.4,0.7$, and 1 & 90 \\
7 & SA & 0,6 , and 12 & 100,300, and 600 & 12,24 , and 96 \\
8 & SA & $0,1,2$, and 2.25 & $100,115,215$, and 229 & $90,96,102$, and 104 \\
\end{tabular}

\section{Callus culture}

The callus for the establishment of cultures were obtained from $T$. peruviana flesh fruit, collected in Medellín city (UTM 18N 435027.97 693421.90). The fruits were disinfected according to the protocol detailed by Arias and coauthors [25]. The explants were extracted from fruit pulp and put aseptically in sterile solid Schenk \& Hildebrandt (SH) medium [30], supplemented with $2 \mathrm{mg} \mathrm{L}^{-1}$ 2,4-dichlorophenoxyacetic acid (2,4D), $0.5 \mathrm{mg} \mathrm{L}^{-1}$ kinetin, $30 \mathrm{~g} \mathrm{~L}^{-1}$ sucrose, $7 \mathrm{~g} \mathrm{~L}^{-1}$ agar and $1 \mathrm{~g} \mathrm{~L}^{-1}$ myoinositol ( $\mathrm{pH} \mathrm{5.8)}$ ), sterilized at $121^{\circ} \mathrm{C}$ and $1 \mathrm{~atm}$ during $20 \mathrm{~min}$. Callus cultures were kept in photoperiod of light $12 \mathrm{~h}-$ darkness $12 \mathrm{~h}$. Sub-cultures were made every three weeks until obtaining friable callus [7].

\section{Cell suspension cultures}

For the establishment of cell suspension cultures, an inoculum of approximately $10 \mathrm{~g}$ of friable callus of T. peruviana obtained from the pulp of its fruits were transferred to $100 \mathrm{~mL}$ of sterile liquid SH medium, supplemented with $2 \mathrm{mg} \mathrm{L}^{-1}$ 2,4-dichlorophenoxyacetic acid (2,4-D), $0.5 \mathrm{mg} \mathrm{L}^{-1}$ kinetin, $30 \mathrm{~g} \mathrm{~L}^{-1}$ sucrose and 
$1 \mathrm{~g} \mathrm{~L}^{-1}$ myoinositol (pH 5.8), in $250 \mathrm{~mL}$ flasks. Cell suspension cultures were set on an orbital shaker (New Brunswick $^{\mathrm{TM}}$ Innova ${ }^{\circledR} 2300$ ). The preservation conditions were $110 \mathrm{rpm}$, photoperiod of light $12 \mathrm{~h}-$ darkness $12 \mathrm{~h}$, temperature $25 \pm 2^{\circ} \mathrm{C}$. Sub-cultures were made every two weeks [25].

\section{Addition of MeJa and SA}

Prior to the elicitation process, cell suspension cultures that were in the $6^{\text {th }}$ day of the exponential phase of its growth curve with biomass 10-gram dry cell weight per liter $\left(\mathrm{g} \mathrm{DW} \mathrm{L}^{-1}\right)$, were transferred to $250 \mathrm{~mL}$ flasks for a final volume of $100 \mathrm{~mL}$ of cell suspension with sterile liquid $\mathrm{SH}$ medium supplemented with a concentration (biomass $2 \mathrm{~g} \mathrm{DW} \mathrm{L}^{-1}$ ). The preservation conditions were mentioned previously.

According to the method established by Mendoza and coauthors [31], MeJa and SA were prepared to a final concentration of 3 and $300 \mu \mathrm{M}$, respectively, in an aqueous solution of ethanol $50 \%(\mathrm{v} / \mathrm{v})$ and were filtersterilized through a $0.45 \mu \mathrm{m}$ Millipore filter (Minisart ${ }^{\circledR}$ ). The control consisted of an aqueous solution of ethanol $50 \%(\mathrm{v} / \mathrm{v})$. The elicitors were added to the cell cultures at day 6 counted from the subdivision (biomass $2 \mathrm{~g}$ DW $\mathrm{L}^{-1}$ ) and the harvest time was $24 \mathrm{~h}$ (Table 1, experiment 1).

\section{Parameters setting for the optimization of total flavonoids}

The values of the operational parameters for the experiments 2 and 6 of Table 1 were established considering the results from experiment 1 and the research conducted by Mendoza [32]. In the same way as described before, cell suspensions that were on the 6th day were taken for subdivisions. The remaining experiments were performed sequentially, according to the results obtained in the previous ones.

\section{Analytical methods}

When the time post-elicitation finished, the cell suspensions were filtered, resulting in two parts: a liquid part and a solid one. These parts were used obtain extracellular and intracellular flavonoids, respectively.

\section{Extracellular flavonoids}

The flavonoids in the liquid part were directly quantified.

\section{Intracellular flavonoids}

The obtained solid part was placed in a convection oven at $60^{\circ} \mathrm{C}$ for $24 \mathrm{~h}$; later, the material was pulverized. For obtaining intracellular flavonoids, $100 \mathrm{mg}$ of sample was weighed and $5 \mathrm{~mL}$ of an aqueous solution of ethanol $50 \%(\mathrm{v} / \mathrm{v})$ was added, in an ultrasonic bath (frequency of $40 \mathrm{kHz}$ ) at $30^{\circ} \mathrm{C}$ for $30 \mathrm{~min}$. The resulting extracts were centrifuged at $3000 \mathrm{rpm}$ for $5 \mathrm{~min}$. The supernatant was then collected and stored for its subsequent quantification.

\section{Flavonoid quantification}

Both extracellular and intracellular flavonoid compounds were determined by flavonoid-aluminum $\left(\mathrm{AlCl}_{3}\right)$ complexation method described by Pekal and Pyrzynska [33]. In a plate of 96 microliters $30 \mu \mathrm{L}$ of sample and $10 \mu \mathrm{L}$ of $5 \%(\mathrm{w} / \mathrm{v}) \mathrm{NaNO}_{2}$ were placed and allowed to settle in darkness for $5 \mathrm{~min} ; 20 \mu \mathrm{L}$ of $2 \%(\mathrm{w} / \mathrm{v})$ $\mathrm{AlCl}_{3}$ was added and allowed to settle for $6 \mathrm{~min}, 60 \mu \mathrm{L}$ of $\mathrm{NaOH} 1 \mathrm{~N}$ was added. After 7 min the absorbance rate was read at a wavelength of $510 \mathrm{~nm}$. Samples without $\mathrm{AlCl}_{3}$ were used as blank.

The calibration curve was fitted using quercetin as standard at concentrations of $500,250,125,62.5$, $31.25,15.625,7.8125$, and $3.90625 \mu \mathrm{g} / \mathrm{mL}$. The calibration curve corresponds to $Y=0.000596618^{*} X+$ $0.0465016\left(R^{2}=0.991\right)$. The samples were analyzed through the equipment MultiskanTM Sky version ESW 1.00.55. The results were expressed in milligrams of quercetin equivalent per gram of dry biomass $(\mathrm{mg} \mathrm{QE} / \mathrm{g}$ DW) for both extracellular and intracellular flavonoids.

\section{Statistical analysis}

The effect of elicitors (Table 1, experiment 1) was analyzed with the statistical software R, version 3.5.2. Flavonoid content results were presented as means \pm standard deviation at extracellular and intracellular level. Differences between treatments were evaluated with a one-way Analysis of Variance (ANOVA) model, based on a complete randomized block design (CRBD), with a significance level of 0.05 . Assumptions of normality, homogeneity of variances, and additivity were evaluated with Shapiro-Wilk test, Levene test, and 
Tukey's test with one degree of freedom, respectively. Multiple pairwise comparisons were conducted by Tukey's honestly significant difference test (Tukey's HSD).

The analyses of all the experiments regarding optimal conditions (2 to 8 ) were carried out with the statistical software Statgraphics ${ }^{\circledR}$ Centurion version XVI. Experiments 2 to 4 and 6 to 7 were run according to central composite designs. Response surface methodology was used in their analyses. Given that both addition time and harvest time were fixed for experiments 5 and 8, simple second order models were fitted. Assumptions of normality and homogeneity variances were carried out with Shapiro-Wilk test and BreuschPagan test, respectively. The results were presented as confidence intervals $(\mathrm{Cl})$ at $95 \%$ confidence level $(\mathrm{CL})$.

\section{RESULTS}

\section{Cell suspension cultures}

To study the effect of elicitors dosage on cell growth, cell suspension cultures of $T$. peruviana were treated with MeJa $(3 \mu \mathrm{M})$ and SA $(300 \mu \mathrm{M})$. The biomass accumulation $24 \mathrm{~h}$ post elicitation was shown in Table 2. The treatments did not present a significant effect $(P=0.492)$. The tested concentration of elicitors did not have an inhibitory impact on the cell growth.

Table 2. Biomass accumulation in cell suspension cultures of $T$. peruviana growth elicited with MeJa and SA.

\begin{tabular}{cccc} 
Elicitor $(\boldsymbol{\mu M})$ & Addition time (days) & Harvest time $(\mathbf{h})$ & Biomass $\left(\mathbf{g ~ D W ~ L}^{-1}\right)$ \\
\hline Control & & & $6.516 \pm 0.986^{\mathrm{a}}$ \\
MeJa $(3)$ & 6 & 24 & $6.039 \pm 1.096^{\mathrm{a}}$ \\
$\mathrm{SA}(300)$ & & & $6.018 \pm 1.373^{\mathrm{a}}$ \\
\hline
\end{tabular}

Note: The results are expressed as the average of $\mathrm{g} D W / \mathrm{L} \pm \mathrm{SD}$. Treatments with a common letter do not differ at $5 \%$ level, according to Tukey's HSD.

\section{Elicitation with MeJa and SA}

Using the elicitation technique with the levels described for experiment 1 (Table 1), the mean total flavonoid content at extracellular level for MeJa, SA, and Control were 0.56, 0.47, and $0.48 \mathrm{mg} \mathrm{QE} / \mathrm{g} \mathrm{DW}$, respectively. The treatments did not present a significant effect $(P=0.606)$. On the other hand, the mean total flavonoid content at intracellular level for MeJa, SA, and Control were 1.97, 2.40, and $1.84 \mathrm{mg} \mathrm{QE} / \mathrm{g}$ DW, respectively. The ANOVA showed a significant effect of treatments $(P=0.0104)$; SA achieved a significant higher mean content of intracellular flavonoids compared to Control. The production of metabolites at the intracellular level was 4.18 times higher than the extracellular level (Figure 1).

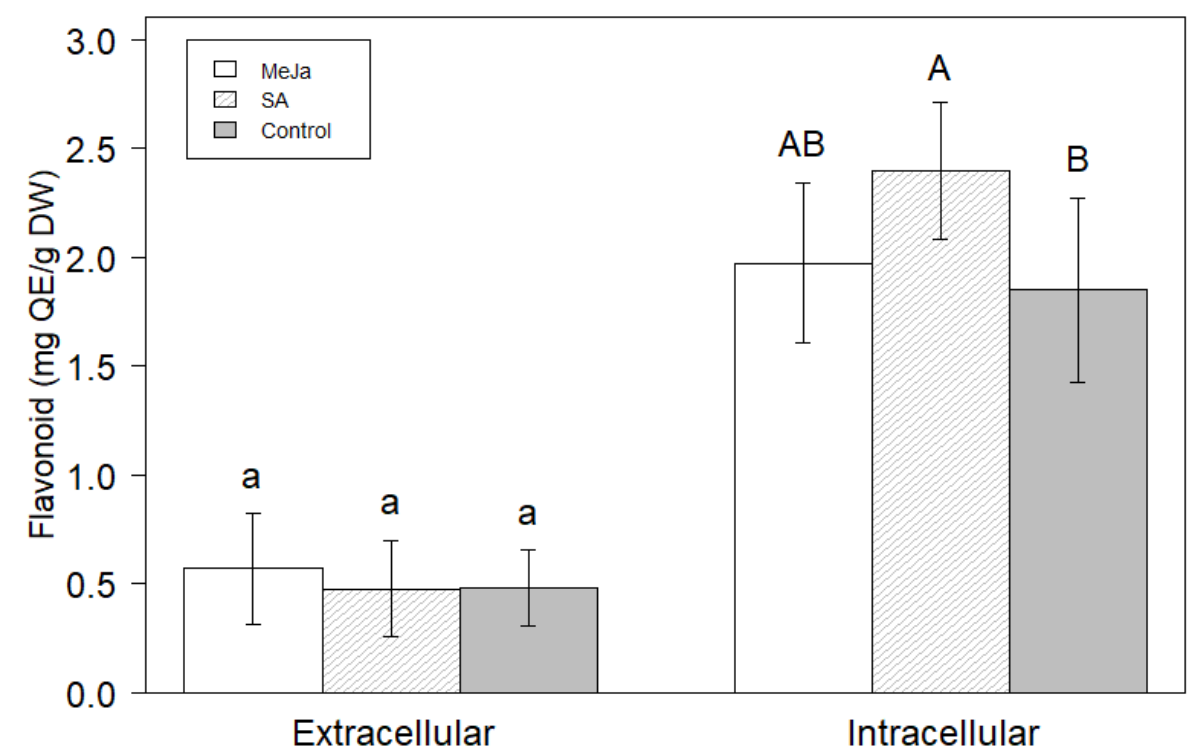

Figure 1. Effect of MeJa $3 \mu \mathrm{M}$ and SA $300 \mu \mathrm{M}$, addition time $6^{\text {th }}$ and harvest time $24 \mathrm{~h}$, on cell suspension cultures of T. peruviana and flavonoids production at extracellular and intracellular levels. The results are expressed as the average of $\mathrm{mg} \mathrm{QE} / \mathrm{g} \mathrm{DW} \pm \mathrm{SD}$. Treatments with a common letter do not differ at $5 \%$ level, according to Tukey's HSD. 


\section{Parameters settings for the optimization of total flavonoids}

Experiments 2 and 6 showed that the content of intracellular flavonoids was 3.84 and 3.93 times higher than the content of extracellular flavonoids, when MeJa and SA were used as elicitors, respectively. For this reason, only the intracellular flavonoids were considered as a response variable in the remaining experiments.

In the process for the optimization of total flavonoid content, the operational parameters showed variations. The maximum flavonoid content was achieved in experiment 5 , where addition time and harvest time were fixed at 5 days and $90 \mathrm{~h}$, respectively. A second-order polynomial model was fitted in function of concentration $(P=0.0052)$. Flavonoids $=4.5567-1.6096^{*}$ concentration $+0.8045^{*}$ concentration ${ }^{2}$. The total flavonoid content estimated was within 4.09 and $4.19 \mathrm{mg} \mathrm{QE} / \mathrm{g} \mathrm{DW}(95 \% \mathrm{CL})$, with MeJa $0.3 \mu \mathrm{M}$, an addition time day 5 and harvest time $90 \mathrm{~h}$ (Figure $2 \mathrm{~d}$ ).

On other hand, the maximum flavonoid content was achieved in experiment 8 , where addition time and harvest time were fixed at 0 day and harvest time $96 \mathrm{~h}$, respectively, a second-order polynomial model was fitted in function of concentration $(P=0.032)$. Flavonoids $=-8.7761+0.2453^{*}$ concentration $0.0012^{*}$ concentration ${ }^{2}$. The total flavonoid content estimated was within 3.31 and $4.18 \mathrm{mg} \mathrm{QE} / \mathrm{g} \mathrm{DW}(95 \%$ $\mathrm{CL}$ ), with SA $100 \mu \mathrm{M}$, an addition time day 0 , and harvest time $96 \mathrm{~h}$ (Figure $2 \mathrm{~g}$ ).

Our results showed that through a process of optimization of parameters such as: concentration, addition time and harvest time, higher flavonoid production were obtained compared to experiments with fixed conditions. Cell suspension cultures of $T$. peruviana elicited with MeJa and SA in optimization experiments increased 2.1 and 1.78 times, respectively, compared to an ordinary experiment. 


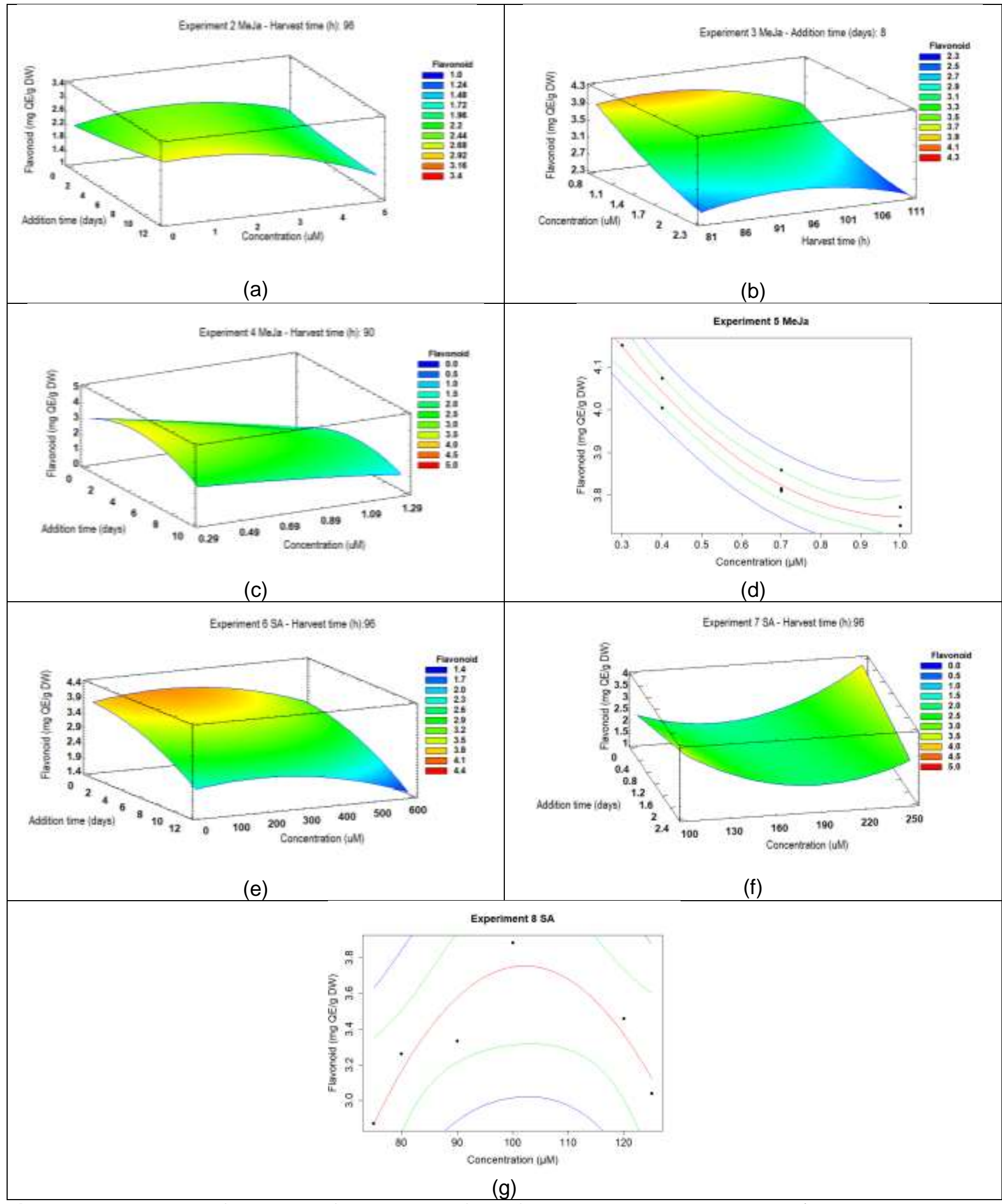

Figure 2. A response surface model of experiments of total flavonoid content. Elicitor MeJa: a) the selected variables addition time (days) and concentration ( $\mu \mathrm{M})$; b) the selected variables concentration $(\mu \mathrm{M})$ and harvest time $(\mathrm{h})$; c) the selected variables addition time (days) and concentration $(\mu \mathrm{M})$. Elicitor SA: e) the selected variables addition time (days) and concentration $(\mu \mathrm{M}) ; \mathrm{f})$ the selected variables addition time (days) and concentration $(\mu \mathrm{M})$. A second-order polynomial model that maximizes the total flavonoid content d) elicitor MeJa and g) elicitor SA; Red line: model fitted, green line: confidence bands, blue line: prediction bands. 


\section{DISCUSSION}

An important group of secondary metabolites are the flavonoids, which are essential constituents of the cells of all higher plants. They exhibit biological and pharmacological activities [34]. Several strategies have been developed to increase the production of secondary metabolites in in vitro cultures, such as manipulating the parameters of the environment and medium, selecting yielding cell clones, precursor feeding, and elicitation [35]. Elicitation is a technique that use a biological, chemical or physical agent to increase the production and accumulation of bioactive compounds by in vitro production systems [15]. Exogenous application of MeJa and SA has been shown to elicit responses in plants that are naturally induced by insect, herbivore and fungal infestation [36].

The maximum biomass accumulation in in vitro cultures of $T$. peruviana was compared with that reported

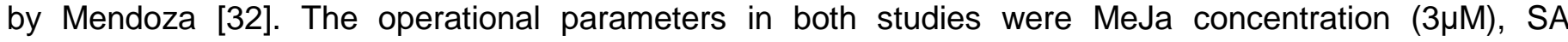
concentration $(300 \mu \mathrm{M})$ and harvest time $24 \mathrm{~h}$. The elicitors were added during the exponential phase; Mendoza [32] added the elicitors on the $4^{\text {th }}$ day, while we did it on the $6^{\text {th }}$ day. Ours results for MeJa and SA were 1.31 and 1.37 times less than those achieved by the aforementioned author, respectively. According Patil and coauthors [37] increased secondary metabolites accumulation upon MeJa elicitation is often accompanied with concurrent decreases in culture growth. Also, they determined molecular changes in Taxus cuspidate cultures by adding MeJa, where all the genes representing histones were downregulated relative to mock-elicited cultures at both 18 and $72 \mathrm{~h}$ post elicitation. Thus, histone gene repression can be correlated to decreased cell division in T. cuspiadate.

In the present research, post-elicitation a change in the color of cell cultures occurred. Similar phenomenon was reported by Mendoza [32]; lower concentrations of MeJa (2-5mg/L) showed significantly higher pigment production compared to the control [38]. The reason could be that there are biochemical or molecular alterations within the cell increase the secondary metabolites production such as phenolic compounds [39]. Isah [40] in his review established that the defense response system becomes activated when intra or extracellular signal is received by receptors in cell plasma membrane, involving their binding accompanied by signal transduction cascade initiation that may result in de novo synthesis or activation of transcription factors responsible for regulating secondary metabolites biosynthesis genes expression.

The total flavonoid content in cell suspension cultures of $T$. peruviana decreased 2.63 and 1.87 times compared with the results of Mendoza and coauthors [31] under the conditions of concentration, addition time and harvesting time mentioned above. Clearly the addition time of elicitors is an important factor in the accumulation of secondary metabolites. According to Caretto and coauthors [41] plants producing defense compounds need to devote their limited resources to survival functions, being forced to make the choice between growing and defending, thus diverting carbon skeletons from the primary to secondary metabolism; to this purpose, several mechanisms can be involved, including the alteration of enzyme kinetics as a reaction to metabolite level and/or induced gene transcription. For this reason, it is implied that the treatment with SA is recommended when the objective is only flavonoid production and not biomass production.

For the optimization of the total flavonoid content effects of operational parameters such as: concentration, addition time, and harvest time were analyzed in detail. Firstly, the concentration of the elicitor plays a major role in cell viability and production of secondary metabolites [42]. In our report, variation in MeJa concentration between experiments 2 and 5 increased total flavonoid production 1.34 times. On the other hand, variation in SA concentration between experiment 6 and 8 decreased total flavonoid production 1.01 times. In T. peruviana, Mendoza and coauthors (31) with MeJa $(3 \mu \mathrm{M})$ and SA $(300 \mu \mathrm{M})$ concentration significantly increased the content of phenolic compounds compared to the control. The application of MeJa and SA in cell suspension cultures in order to increase the secondary metabolites has been reported in a wide variety of plants species [43]. In Hypericum perforatum Wang and coauthors [44] and in Menta piperita, Krzyzanowska and coauthors [45] the flavonoid content and rosmarinic acid increased with MeJa $100 \mu \mathrm{M}$; conversely, the content of secondary metabolites decreased with $50-200 \mu \mathrm{M}$, respectively. Giri and Zaheer [46] indicated in their review that in different in vitro plant cell culture systems the addition of JA, MeJa and SA ranged in concentration from 5.0 to $500 \mu \mathrm{M}$; in a realistic appraisal of literature on the concentrations of elicitors revealed that, $100 \mu \mathrm{M}$ MeJa and SA also used in majority of studies. Thiruvengadam and coauthors [47], Sun and coauthors [48], Wang and coauthors [49], Bahieldin and coauthors [50], and Gabotti and coauthors [51] have reported that elicitation in different cell suspension cultures with MeJa and SA increases the expression level of different enzymes involved in flavonoid biosynthetic pathways [52]. MeJa inhibits catalase activity and stimulates PAL increasing the flavonoids production, where SA induces gene regulation related to the biosynthesis of secondary metabolites in plants [20]. 
Secondly, the addition time depends on the cell growth stage of the in vitro culture. Four stages can be identified in the cell growth curve of $T$. peruviana: a lag phase, an exponential phase, a stationary phase and a death phase [25]. In our research, the cultures were elicited with MeJa on late exponential phase $12^{\text {th }}$ day and mid-exponential phase $5^{\text {th }}$ day (experiments 2 and 5 , respectively), the addition time was reduced 2.4 times. On the other hand, the cultures were elicited with SA on lag phase the 0 day (experiments 6 and 8), that is, the same day the cell cultures were subdivided. In T. peruviana Mendoza and coauthors [31] obtained the highest contents of phenolic compounds on early exponential phase $\left(4^{\text {th }}\right.$ day) and Arias and coauthors [25] reported the highest peruvoside production on lag phase (0 day). To obtain secondary metabolites in plant cell cultures of $T$. peruviana, the addition time of elicitors must be on lag and exponential phase. In Corylus avellana Salehi and coauthors [53] reported that fungal extract of Camarosporomyces flavigenus added on late exponential phase significantly increased paclitaxel content compared to addition on midexponential phase. According to the plant species, the elicitor treatment at different growth phase may result in varied response relating to growth and biosynthesis of secondary metabolites [42].

Finally, the harvest time influences the growth and secondary metabolite production [42]. This study found that the maximum content of flavonoids was achieved for MeJa (90 h) and SA (96 h); for MeJa the harvest time was 1.6 times. In T. peruviana Mendoza and coauthors [31] reported than at an incubation time of $96 \mathrm{~h}$ the flavonoid increased significantly compared to the control. The type of elicitor and its time postelicitation in the cell culture influence in the gene expression of the biosynthetic pathways [54]. Several studies have reported the importance of the time post-elicitation in in vitro cultures to produce secondary metabolites. In Papaver orientale Mohammad and coauthors [54] demonstrated that morphine biosynthesis began at $48 \mathrm{~h}$, in contrast to the codeine biosynthesis that began at $24 \mathrm{~h}$. In H. perforatum Gadzovska and coauthors [55] reported that JA treatments affected secondary metabolite production during the time of culture, a 6-fold increase of phenolic compounds and flavanols after $1-7$ days of JA elicitation. Also, the activities of two key enzymes were monitored, a 6 - 8-fold increase of PAL and CHI. The exposition time of the elicitor is important to maximize the final concentration of a particular metabolite [56].

\section{CONCLUSIONS}

The current research showed that application of elicitors MeJa and SA in plant cell cultures of $T$. peruviana increased total flavonoid content, compared with a control without their application in in vitro conditions. MeJa at $3 \mu \mathrm{M}$ and SA $300 \mu \mathrm{M}$ concentration, addition time 6 days, and harvest time $24 \mathrm{~h}$ increase the total flavonoid content in 1.07 and 1.3 times, respectively, compared to the control culture. On the other hand, parameters considered in the optimization process affect the total flavonoid production; MeJa $0.3 \mathrm{Mm}$ concentration, time addition $5^{\text {th }}$ day and harvest time $90 \mathrm{~h}$ resulted in $4.14 \mathrm{mg}$ QE/g DW. SA $100 \mu \mathrm{M}$ concentration, time addition 0 day and harvest time 96 resulted $3.75 \mathrm{mg} \mathrm{QE} / \mathrm{g} \mathrm{DW}$. Thus, exogenous application of MeJa and SA with certain ideal parameters can be used in cell suspension cultures of $T$. peruviana in bioreactors so as to achieve enhanced production of flavonoid compounds.

Funding: This study was supported by Universidad Nacional de Colombia, Sede Medellín and by Departamento Administrativo de Ciencia, Tecnología e Innovación de Colombia - COLCIENCIAS (Project Code 110177657868).

Acknowledgments: To the Industrial Biotechnology research group, at the Laboratorio de Bioconversiones Universidad Nacional de Colombia, Sede Medellín.

Conflicts of Interest: "The authors declare no conflict of interest".

\section{REFERENCES}

1. Bera S, Saha S. Biosynthesis and characterization of Thevetia peruviana leaf extract capped CdTe nanoparticles in photoconductive and photovoltaic applications. Mater Today Proc. 2018;5(2):3476-85. doi: 10.1016/j.matpr.2017.11.594

2. Bora M, Gogoi P, Deka D, Kakati D. Synthesis and characterization of yellow oleander (Thevetia peruviana) seed oil-based alkyd resin. Ind Crops Prod. 2014;52:721-8. doi: 10.1016/j.indcrop.2013.11.012

3. Rahman N, Rahman H, Haris M, Mahmood R. Wound healing potentials of Thevetia peruviana: Antioxidants and inflammatory markers criteria. J Tradit Complement Med. 2017;7(4):519-25. doi: 10.1016/j.jtcme.2017.01.005

4. Ahmad T, Hamid A, Sharma A, Bhardwaj U. Thevetia peruviana: A multipurpose medicinal plant a review. Int J Adv Res. 2017;5(8):486-93. doi: 10.21474/IJAR01/5081

5. Siwach $P$, Grover K, Rani A. The influence of plant growth regulators, explant nature and sucrose concentration on in vitro callus growth of Thevetia peruviana Schum. Asian J Biotecnnology. 2011;3(3):280-92. doi: 10.3923/ajbkr.2011.280.292 
6. Kishan S, Kumar A, Vimlesh M, Mubeen U, Alok S. A review on Thevetia peruviana. Int Res J Pharm. 2012;3(4):747.

7. Mendoza D, Arias J, Cuaspud O, Arias M. Phytochemical screening of callus and suspensions cultures of Thevetia peruviana. Brazilian Arch Biol Technol. 2020;63:1-14. doi: 10.1590/1678-4324-2020180735

8. Kohls S, Scholz-Böttcher BM, Teske J, Zark P, Rullkötter J. Cardiac glycosides from yellow oleander (Thevetia peruviana) seeds. Phytochemistry. 2012;75:114-27. doi: 10.1016/j.phytochem.2011.11.019

9. Khoddami A, Wilkes M, Roberts T. Techniques for analysis of plant phenolic compounds. Molecules. 2013;18(2):2328-75. doi: 10.3390/molecules 18022328

10. Lattanzio V. Phenolic compounds: Introduction. In: Natural products: Phytochemistry, botany and metabolism of alkaloids, phenolics and terpenes. 2013. p. 1544-73. doi: 10.1007/978-3-642-22144-6

11. Lin D, Xiao M, Zhao J, Li Z, Xing B, Li X, et al. An overview of plant phenolic compounds and their importance in human nutrition and management of type 2 diabetes. Molecules. 2016;21(10). doi: 10.3390/molecules21101374

12. Kim J, Shim Y. Method validation of analytical method for 12 flavonol glycosides in foods using ultra highperformance liquid chromatography coupled with photodiode array detection. Food Sci Biotechnol. 2016;25(3):65964. doi: 10.1007/s10068-016-0116-5

13. Ncube B, Finnie J, Van Staden J. Quality from the field: The impact of environmental factors as quality determinants in medicinal plants. South African J Bot. 2012;82:11-20. doi: 10.1016/j.sajb.2012.05.009

14. Yi TG, Park Y, Park J, Park N II. Enhancement of phenolic compounds and antioxidative activities by the combination of culture medium and methyl jasmonate elicitation in hairy root cultures of Lactuca indica L. Nat Prod Commun. 2019;1-9. doi: 10.1177/1934578X19861867

15. Dias M, Sousa M, Alves R, Ferreira I. Exploring plant tissue culture to improve the production of phenolic compounds: A review. Ind Crops Prod. 2016;82:9-22. doi: 10.1016/j.indcrop.2015.12.016

16. Marchev A, Georgiev M. Plant in vitro systems as a sustainable source of active ingredients for cosmeceutical application. Molecules. 2020;25(2006):2-19. doi: 10.3390/molecules25082006

17. Andi S, Gholami M, Ford C, Maskani F. The effect of light, phenylalanine and methyl jasmonate, alone or in combination, on growth and secondary metabolism in cell suspension cultures of Vitis vinifera. J Photochem Photobiol B Biol. 2019;1-8. doi: 10.1016/j.jphotobiol.2019.111625

18. El-Ashry A, Gabr A, Arafa N, El-Bahr. Moha E. Rutin accumulation in gardenia calli cultures as a response to phenyl alanine and salicylic acid. Bull Natl Res Cent. 2019;43(141):1-14. doi: 10.1186/s42269-019-0174-y

19. Liu ZB, Chen JG, Yin ZP, Shangguan XC, Peng DY, Lu T, et al. Methyl jasmonate and salicylic acid elicitation increase content and yield of chlorogenic acid and its derivatives in Gardenia jasminoides cell suspension cultures. Plant Cell Tissue Organ Cult. 2018;134(1):79-93. doi: 10.1007/s11240-018-1401-1

20. Jacob A, Thomas J. Flavonoids from cell suspension culture of Ocimum tenuiflorum and its enhancement using response surface methodology. Drug Invent Today. 2019;11(9):2188-93.

21. Al-Khayri JM, Naik PM. Elicitor-induced production of biomass and pharmaceutical phenolic compounds in cell suspension culture of date palm (Phoenix dactylifera L.). Molecules. 2020;25(20):1-10. doi: 10.3390/molecules25204669

22. Kamel S, Mahfouz H, Blal H, Said M, Mahmoud M. Effects of salicylic acid elicitor and potassium fertilizer as foliar spray on canola production in the reclaimed and in Ismailia Governorate, Egypt. Cercet Agron Mold. 2016;49(1):819. doi: 10.1515/cerce-2016-0007

23. Reyes M, Lobos T, Cardemil L, Nunes A, Retamales J, Jaakola L, et al. Methyl jasmonate: An alternative for improving the quality and health properties of fresh fruits. Molecules. 2016;21(6):1-18. doi: 10.3390/molecules21060567

24. Arias J, Zapata K, Rojano B, Peñuela M, Arias M. Cardiac glycosides, phenolic compounds and antioxidant activity from plant cell suspension cultures of Thevetia peruviana. Rev UDCA Actual Divulg Científica. 2017;20(2):353-62.

25. Arias M, Angarita M, Restrepo J, Caicedo L, Perea M. Elicitation with methyl-jasmonate stimulates peruvoside production in cell suspension cultures of Thevetia peruviana. Vitr Cell Dev Biol - Plant. 2010;233-8. doi: 10.1007/s11627-009-9249-z

26. Tabata H. Production of paclitaxel and the related taxanes by cell suspension cultures of taxus species. Curr Drug Targets. 2006;7(4):453-61. doi: 10.2174/138945006776359368

27. Namdeo A. Plant cell elicitation for production of secondary metabolites: A review. Pharmacogn Rev. 2007;1(2):227-31.

28. Murthy HN, Kim Y, Jeong C, Kim S, Zhong J, Paek K. Production of ginsenosides from adventitious root cultures of Panax ginseng. In: production of biomass and bioactive compounds using bioreactor technology. 2014. p. 625-51. doi: 10.1007/978-94-017-9223-3_24 
29. Ramachandra S, Ravishankar G. Plant cell cultures: Chemical factories of secondary metabolites. Biotechnol Adv. 2002;20(2):101-53. doi: 10.1016/S0734-9750(02)00007-1.

30. Schenk R, Hildebrandt A. Medium and techniques for induction and growth of monocotyledonous and dicotyledonous plant cell cultures. Can J Bot. 1972;50(12):199-204. doi: 10.1139/b72-026

31. Mendoza D, Cuaspud O, Pablo J, Ruiz O, Arias M. Effect of salicylic acid and methyl jasmonate in the production of phenolic compounds in plant cell suspension cultures of Thevetia peruviana. Biotechnol Reports. 2018;19(63). doi: 10.1016/j.btre.2018.e00273

32. Mendoza D. Estudio metabolómico de células de Thevetia peruviana (Pers.) K. Schum (Apocynaceae) cultivadas en suspensión, como respuesta al tratamiento con dos elicitores de la biosíntesis de compuestos fenólicos. Universidad Nacional de Colombia; 2019.

33. Pekal A, Pyrzynska K. Evaluation of aluminium complexation reaction for flavonoid content assay. Food Anal Methods. 2014;7(9):1776-92. doi: 10.1007/s12161-014-9814-x

34. Santos E, Salesa B, Ferriani A, Teixeira SD. Flavonoids: Classification, biosynthesis and chemical ecology. In: Flavonoids - From Biosynthesis to Human Health. 2017. p. 3-16. doi: 10.5772/67861

35. Jedinák A, Faragó J, Pšenáková I, Maliar T. Approaches to flavonoid production in plant tissue cultures. Biol - Sect Cell Mol Biol. 2004;59(6):697-710.

36. Shahin $\mathrm{H}$. Enhanced production of secondary metabolites by methyl jasmonate and silver nanoparticles elicitation in tissue culture of Catharanthus roseus ( Apocynaceae ). Asian J Pharm Sci. 2018;57:62-9.

37. Patil R, Lenka S, Normanly J, Walker E, Roberts S. Methyl jasmonate represses growth and affects cell cycle progression in cultured Taxus cells. Plant Cell Rep. 2014;33(9):1479-92. doi: 10.1007/s00299-014-1632-5

38. See KS, Bhatt A, Keng CL. Effect of sucrose and methyl jasmonate on biomass and anthocyanin production in cell suspension culture of Melastoma malabathricum ( Melastomaceae ). Int J Trop Biol. 2011;59(June):597-606.

39. Gallão M, Cortelazzo Â, Fevereiro M, de Brito E. Biochemical and morphological responses to abiotc elicitor chitin in suspension-cultured sugarcane cells. Brazilian Arch Biol Technol. 2010;53(2):253-60. doi: 10.1590/S151689132010000200002

40. Isah T. Stress and defense responses in plant secondary metabolites production. Biol Res. 2019;52(39):1-25. doi: 10.1186/s40659-019-0246-3

41. Caretto S, Linsalata V, Colella G, Mita G, Lattanzio V. Carbon fluxes between primary metabolism and phenolic pathway in plant tissues under stress. Int J Mol Sci. 2015;16(11):26378-94. doi: 10.3390/ijms161125967

42. Narayani M, Srivastava S. Elicitation : A stimulation of stress in in vitro plant cell / tissue cultures for enhancement of secondary metabolite production. Phytochem Rev. 2017;16(6):1227-52. doi: 10.1007/s11101-017-9534-0

43. Ramirez K, Vidal H, Hidalgo D, Moyano E, Golenioswki M, Cusidó RM, et al. Elicitation, an effective strategy for the biotechnological production of bioactive high-added value compounds in plant cell factories. Molecules. 2016;21(2):1-24. doi: 10.3390/molecules21020182

44. Wang J, Qian J, Yao L, Lu Y. Enhanced production of flavonoids by methyl jasmonate elicitation in cell suspension culture of Hypericum perforatum. Bioresour Bioprocess. 2015;2(5):1-9. doi: 10.1186/s40643-014-0033-5

45. Krzyzanowska J, Czubacka A, Pecio L, Przybys M, Doroszewska T, Stochmal A, et al. The effects of jasmonic acid and methyl jasmonate on rosmarinic acid production in Mentha $\times$ piperita cell suspension cultures. Plant Cell Tissue Organ Cult. 2012;108(1):73-81. doi: 10.1007/s11240-011-0014-8

46. Giri C, Zaheer M. Chemical elicitors versus secondary metabolite production in vitro using plant cell, tissue and organ cultures: recent trends and a sky eye view appraisal. Plant Cell Tissue Organ Cult. 2016;126(1). doi: 10.1007/s11240-016-0985-6

47. Thiruvengadam M, Kim S, Chung I. Exogenous phytohormones increase the accumulation of health-promoting metabolites, and influence the expression patterns of biosynthesis related genes and biological activity in Chinese cabbage (Brassica rapa spp. pekinensis ). Sci Hortic (Amsterdam). 2015;193:136-46. doi: 10.1016/j.scienta.2015.07.007

48. Sun Z, Hou S, Yang W, Han Y. Exogenous application of salicylic acid enhanced the rutin accumulation and influenced the expression patterns of rutin biosynthesis related genes in Fagopyrum tartaricum Gaertn leaves. Plant Growth Regul. 2012;68(9):9-15. doi: 10.1007/s10725-012-9688-0

49. Wang $\mathrm{H}$, Wang $\mathrm{W}$, Huang $\mathrm{W}, \mathrm{Xu} \mathrm{H}$. Effect of salicylic acid on the gene transcript and protein accumulation of flavonoid biosynthesis-related enzymes in Vitis vinifera cell suspension cultures. Hortic Sci. 2017;52(12):1772-9. doi: 10.21273/HORTSCI12515-17

50. Bahieldin A, Atef A, Edris S, Gadalla N, Al-matary M, Al-Kordy M, et al. Stepwise response of MeJA-induced genes and pathways in leaves of C. roseus. Comptes Rendus - Biol. 2018;341(9-10):411-20. doi: 10.1016/j.crvi.2018.10.001 
51. Gabotti D, Locatelli F, Cusano E, Baldoni E, Genga A, Pucci L, et al. Cell suspensions of Cannabis sativa (var. futura): Effect of elicitation on metabolite content and antioxidant activity. Molecules. 2019;24(22). doi: $10.3390 /$ molecules24224056

52. Thiruvengadam M, Rekha K, Rajakumar G, Lee T, Kim S, Chung I. Enhanced production of anthraquinones and phenolic compounds and biological activities in the cell suspension cultures of Polygonum multiflorum. Int J Mol Sci. 2016;17(11):1-16. doi: 10.3390/ijms17111912

53. Salehi M, Moieni A, Safaie N, Farhadi S. Whole fungal elicitors boost paclitaxel biosynthesis induction in Corylus avellana cell culture. PLoS One. 2020;15(7 July):1-17. doi: 10.1371/journal.pone.0236191

54. Mohammad S, Mohammad H, Naghavi R. Production and gene expression of morphinan alkaloids in hairy root culture of Papaver orientale L. using abiotic elicitors. Plant Cell, Tissue Organ Cult. 2015. p.1-11. doi: 10.1007/s11240-015-0927-8

55. Gadzovska S, Maury S, Joseph C, Hagege D, Delaunay A, Spasenoski M. Jasmonic acid elicitation of Hypericum perforatum $\mathrm{L}$. cell suspensions and effects on the production of phenylpropanoids and naphtodianthrones. Plant Cell Tissue Organ Cult. 2007;89:1-13. doi: 10.1007/s11240-007-9203-x

56. Komaraiah P, Kishor PBK, Carlsson M, Magnusson K, Mandenius C. Enhancement of anthraquinone accumulation in Morinda citrifolia suspension cultures. Plant Sci. 2005;168:1337-44. doi: 10.1016/j.plantsci.2005.01.017

(C) (5) 2021 by the authors. Submitted for possible open access publication under the terms and
conditions of the Creative Commons Attribution (CC BY NC) license EY NC (https://creativecommons.org/licenses/by-nc/4.0/). 